\title{
Wolfram von Eschenbach
}

\author{
lierausgegeben \\ von \\ Albert Leitzmann
}

Fünftes heft:

Willehalm buch VI bis IX;

Titurel ; lieder

Zweite, verbesserte auflage

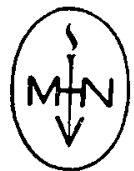

Halle (Saale)

Verlag von Max Niemeyer

1926 


\section{Alle rechte,}

auch das der ühersetzung in fremde sprachen, vorbehalten Copyright by Max Niemeyer, Verlag, Halle (Saale), 1926

Altdentsche textbibliothek, begründet von $\mathrm{H} . \mathrm{Paul} t$, herausgegeben von $\mathrm{G}$. Baesecke

$$
\text { nr. } 16
$$

